\title{
Curriculum Construction and Custom Publishing - An Academic Perspective
}

\author{
Joan Richardson, Ross Smith, and Audra Lukaitis \\ School of Business Information Technology and Logistics, \\ RMIT University, Australia \\ joan.richardson@rmit.edu.au, ross.smith@rmit.edu.au, \\ audra.lukaitis@rmit.edu.au \\ Ryan O'Hare \\ Pearson Learning Solutions, Australia \\ ryan.ohare@pearson.com.au
}

\begin{abstract}
Increasingly, changes in the policies of university, government and professional bodies demand that subject and course design are role or outcome driven with articulated graduate attributes. This has had an immediate impact on both the academics designing subjects and the publishers responding to their needs with customized resources or "custom publishing".

This is particularly the case for higher education where students may be using the same resources in a range of learning and teaching spaces, interacting with varied resource delivery modes, across geographical boundaries and within differing cultural environments. Clearly, the environment is becoming more complex for academics. How do we provide appropriate resources for students with diverse learning needs and styles, across learning spaces and geographical boundaries?

This paper presents various academic perspectives of custom publishing and curriculum construction. The academic perspectives are drawn from a case study of the development of a custom text by one of the authors, supplemented by consideration of a qualitative survey of a number of academics with custom publishing experience.
\end{abstract}

Key words: custom publishing, curriculum construction, e-texts, graduate attributes, online curriculum

\section{Introduction}

Material published as part of this publication, either on-line or in print, is copyrighted by the Informing Science Institute. Permission to make digital or paper copy of part or all of these works for personal or classroom use is granted without fee provided that the copies are not made or distributed for profit or commercial advantage AND that copies 1) bear this notice in full and 2) give the full citation on the first page. It is permissible to abstract these works so long as credit is given. To copy in all other cases or to republish or to post on a server or to redistribute to lists requires specific permission and payment of a fee. Contact Publisher@InformingScience.org to request redistribution permission.
The globalisation of work and the rapid rate of technology innovation that supports communication across vast distances presents opportunities and challenges for academic curriculum resource development.

Increasingly, academics are designing subjects that cater to tertiary students from diverse cultural backgrounds destined for a range of professional graduate roles. The purpose of education is 
not solely academic or vocational - it is also expected to address personal development [Marginson, 1994]. Students must learn how to continually grow, and develop in response to changed circumstances, to apply professional discipline based knowledge in the work-place [Jaques, 1976].

Despite the range of student expectations and graduate professional outcomes, all students enrolled in a subject are expected to achieve similar learning objectives. Inherent diversity in student needs adds to the complexity of curriculum design. As higher education has globalised, students can also be using the same resources in a range of learning and teaching spaces, varied resource delivery modes, and within differing cultural environments. How do we provide appropriate resources for students with diverse learning needs and styles, across learning spaces and geographical boundaries?

To enable more timely learning and teaching resource development, publishers have invested in Content Management Systems and technologies that provide academics with speedier access to a vast array of digitised textbooks and associated resources. With the emergence of custom publishing, subject titles and discipline codes can be aligned with content; academics are directed to peruse publications with relevant material, enabling choice from a number of texts rather than a single publication.

Seeking to address the challenges above, the case discussed in this research-in-progress paper describes some of the potential benefits and pitfalls of custom publishing. Further, this paper describes a customization process that has been taken a step further and incorporates resources for two subjects into one text. The text in question is 'Working Communications' a business textbook designed for the Information Technology (IT) and business end-user market.

Technology supported delivery components drove the selection of chapters from three traditional texts chosen to augment the discipline and generic skill acquisition in two subjects. Pearson Education Australia, a major educational publisher, provided the resources for "Industry Project" and its pre-requisite subject "Business Communications". These curriculum areas are important to the education of work-ready students, equipping them to obtain jobs in the business professions. The text, now in its 1st edition, is currently prescribed for first year undergraduate business Information Systems (IS) student cohorts in Australia, Hong Kong and Vietnam.

Technology provided part of the solution. The curriculum resources for the two newly developed subjects were needed within a short time-frame. Custom publishing enabled academics to quickly identify desirable learning and teaching resources from three publications. The construction of the customised text then combined the text elements with online deliverables. PowerPoint lectures, tutorial and workshop activities and online quizzes were part of the package. The technology and the publishers enabled fast, cheap creation of course resources that directly aligned the scheduled subject learning and assessment activities with a custom publication. The academic curriculum development process was straightforward, efficient, saved institutional time and, to an extent, resources were able to be "contextualised".

This paper describes the process used to choose digital resources and the components for the text; how this influences the curriculum development process and subject delivery will be discussed. Central to the paper is the key research question: How might custom publishing facilitate delivery of appropriate learning resources to students, with diverse learning needs and styles? The approach taken focuses on capturing and reporting relevant academic perspectives.

In this paper, the imperative for the teaching of communication skills as a curriculum component, a driver of this project, is first introduced. The research method, drawing on both case study and qualitative survey approaches is then described. Results from the case study are presented, in particular academic perspectives drawn from the case study and insights into the process of curricu- 
lum selection that underpinned the custom publishing undertaken. Subsequently, various academic perspectives of custom publishing identified via the qualitative survey are reported. The paper concludes with a short summary and some concluding observations.

\section{Communication Skills as a Curriculum Component}

In November 2007, the Seoul Accord was agreed by representatives from Australia, Britain, Canada, Japan, Korea and the US (ABET). The Seoul Accord established a draft set of graduate attributes expected of students entering the ICT profession. Communication is one of the specified graduate attributes for computing professionals:

"A graduate must be able to communicate effectively with the computing community and with society at large about complex computing activities by being able to comprehend and write effective reports, design documentation, make effective presentations and give and understand clear instructions [Seoul Accord, 2007]”.

Likewise, the Australian Computer Society (ACS) requires communication topics, including oral and written presentations, technical report writing, writing user documentation and the development of effective interpersonal skills, incorporated into ICT curricula [ACS, 2009].

The Australian Department of Education, Employment and Workplace Relations (DEST) published a report in 2002 identifying generic employability skills including: communication; team work; problem-solving; initiative/enterprise; planning and organisation; self-management; learning; and technology [DEST 2002]. It is posited that generic skills are needed if graduates are to apply their knowledge across a range of industry domains. These graduate attributes assist the individual to transfer knowledge and skills from the educational domain to work practice. In order to respond to the expressed industry need for graduates with a strong generic skill base the content of educational products and associated structures have changed.

Changes in policies of the university, government and professional bodies have demanded also that subject and course design are role or outcome driven and include communication skills as a graduate attribute. This has had an immediate impact on both the academics designing subjects and the publishers responding to their needs with customized resources. Communication skills are a crucial component of university graduate attributes and subject capabilities as they are integral to the application of professional skills in the workplace.

In some courses, such as the case study described in this paper, subjects are developed to focus attention on the development of communication skills for work. In other courses across the university, components of the communications discipline area are included to improve students' capacity for industry practice in their profession. Custom publishing as a business process has the capacity to support either method of teaching communication skills and knowledge. In particular, the latter curriculum need - where an IS academic may just need to teach and evidence a student's capacity to communicate using a business report within a professional context - can be supported by a diverse selection of resources, assembled using a custom publishing model..

It should be noted, however, that as communication skills are acquired through completing a variety of tasks in a range of contexts, an academic may need to contextualise the resources adopted during the custom publishing process. For example, there is an assumption that learning about digital communication, presentations and resume writing in a class will enable students to produce professional documents, interview well and win jobs in a relevant workplace setting.

The need for an efficient process to support academics as they create and deliver curriculum across the globe, to professionally diverse cohorts, is obvious. How they integrate components such as communication into a traditional IS subject without interfering with the natural logic of the narrative is more difficult. 


\section{Research Method}

The results reported herein seek to capture academic perspectives of custom publishing. The academic perspectives are drawn from a case study of the development of the "Working Communications" custom text by one of the authors, with the development activities described drawing upon the constructional alignment literature. The academic perspectives drawn from this case study are supplemented by consideration of a qualitative survey of a number of academics with custom publishing experience. This survey has been facilitated by the publishers (Pearson) of the "Working Communications" text. The key questions asked however (see later), were open, and not framed to focus specifically on the Pearson approach to custom publishing or Pearson products.

\section{Research Approach - the Case Study Method}

The research which has underpinned the capture of the academic perspectives reported follows a case study method, with the case being the development of the "Working Communications" text by one of the authors.

Yin [2002] defines a case study as an empirical inquiry that investigates a contemporary phenomenon within its real-life context, especially when the boundaries between phenomenon and context are not clearly evident. Case study methodology is particularly well-suited to the field of IT, where the focus is on organizational rather than technical issues [Benbasat et al, 1987]. The form and content of case studies vary greatly depending on the audience and context. Yin [2002] proposes the use of multiple sources of evidence as the distinguishing feature of case studies; McBurney [2001] maintains that it is the individuality of the case or situation that characterizes case studies. Case studies may include information gathered from a single source or from a variety of sources including naturalistic observations, archival records and interviews with the case subjects and with those who regularly interact with them.

The case study is interpreted in this paper using ideas drawn from the literature that recognizes the need for pedagogy to be underpinned by constructional alignment [Biggs, 2003]. It should be noted, however, that evidence to support definitively that the "Working Communications" suite of resources enable students to construct meaning from what they learnt is not available from this research to date. For example, students' ability to utilize the resumes and cover letters developed and the generic skills acquired, to obtain professional employment, has not yet been tested. However the process used by the academics to align the planned learning activities with the learning outcomes followed the processes requisite to establish constructional alignment.

\section{Research Approach - the Qualitative Survey}

The insights drawn from the case study are supplemented by consideration of a qualitative survey, conducted by Pearson Education publishers, of academics currently using customized texts in a range of discipline areas in Australia and the US. The respondents were academics who use Pearson Education customized texts from the US Department of Education, Florida A\&M University, San Francisco State University [Management], Rio Salado College, University of Maryland University College, University of South Carolina-Columbia and San Antonio College [Speckler, 2008]. In Australia, nine academics using custom texts were surveyed by Pearson Education Australia. The range of disciplines using customized texts included Science Concepts and Global Systems, Professional Writing, Business, Management and Teacher Education. In this survey the academics responding were encouraged to focus on what takes place in practice. Why did they choose a customized text? What difference did the customized text make to the students? Was the use of the customized text successful? 
The following sections present findings focusing on academic perspectives, of creating the "Working Communications" resources in particular, and Custom Publishing in general.

\section{Results: "Working Communications" - Some Academic Perspectives}

Reflection on the creation of the "Working Communications" resources, highlighted the following key insights:

- Educators in the higher education marketplace recommend texts and digital resource suites for subjects they have designed. Within many higher education institutions this task has become complex, as the subjects are delivered to many cohorts of students dispersed sometimes across the globe, by teaching teams rather than individuals. It is, therefore, hard to find traditional texts that reflect the chronological order of a proposed schedule for delivery of theory and concepts in a subject. Technology, however, has enabled publishers to respond to these difficulties with custom publishing. Not only are linear solutions tailored to specific teaching and learning needs, but tight alignment between learning objectives, activities and assessments are easier to construct for the academics. Technology has enabled publishers to open their vast and rich library of content to provide fast construction of texts, which are often cheaper. Custom publishing enabled the achievement of this requirement.

- To enable people to apply the knowledge gained in their university education in the business environment they require both general intellectual abilities and knowledge of discipline specific content areas. In the present case study, a custom text was designed to address the needs of two subjects. The aim of the suite of two subjects was to equip students with specialist knowledge, an ability to communicate effectively using technology to support global interaction and general business knowledge reflected in the tools required in order to obtain a professional graduate job. Custom publishing enabled the achievement of this requirement.

- As global workplaces in the 21st century require employees who can communicate effectively in a range of challenging circumstances, subjects must provide a skill base and practice in context, with increasing depth [Bloom, 1956]. This practical course offers students critical knowledge about the complexities of modern communication in organizations. Students have the opportunity to develop and practice their verbal, non verbal, written and digital communication techniques in a range of simulated workplace situations, as well as through liaison with organizations. Each activity undertaken may not be intrinsically beneficial, however, its potential to reinforce professional learning acquired in traditional university environments whilst ensuring generic skill development is irreplaceable. These skills will be particularly relevant for students as they transition to the world of work and advance in their careers. Custom publishing enabled the achievement of this requirement

- Competition in the graduate employment market has reinforced the importance of developing students' graduate employability skills [Beckett and Hager, 2002]. Despite the plethora of available resources designed to enable teaching and learning in communication a paucity of resources was found to support digital communication. This is surprising as the technologies used by the publishers to store, organize, communicate and deliver text resources to keep abreast of their marketplace are the same as those that now need to be taught. Topic definitions in many business communications texts include resume writing but the instructional materials often do not include searching for the job online, researching the prospective organization on the Web, emailing human resources or acquiring the position description and perhaps delivering part of the resume as a video on YouTube. Custom publishing enabled the achievement of this requirement. 


\section{Results: "Working Communications" - The Academic Process}

Several studies support the concept of aligning assessment with learning [Ramsden, 1992; Biggs, 2003, Henderson and McWilliams, 2008]. This constructive approach to learning fits well with the concept of assessment for learning [Ramsden, 1992]. In this vein, a portfolio model for student assessment was adopted in the present case, supporting learning in a business program in which the student produces a portfolio of learning, based on an evidence-based approach in which the criteria for assessment are jointly developed and linked to learning outcomes. The curriculum was designed to align learning activities and assessment tasks with learning outcomes. This process is absolutely crucial to effective delivery when the resources are drawn from a number of publications which could otherwise lead to serious fragmentation of the learning narrative. The design of the subject curriculum must include each topic, the associated method of delivery and assessment. An additional task is encasing the professional context narrative.

In this paper, only one topic from the custom text is described, as a means of illustrating the development approach employed, as depicted in Figure 1.

Learning activities will be predominantly experiential in nature with opportunities to apply and practice effective communication skills and techniques in a range of different business contexts. This was enabled through the range of choices available from CourseConnect online Courseware. Topics were designed around the learning objectives for each of the courses. Activities were then chosen to allow students to add samples and templates to their e-portfolio. The initial workshop activities were based on a range of small cases. In the second subject, Industry Project, the "Study Hall" activities were used, as the case was more complex and required an understanding of context as well as the application of skills.

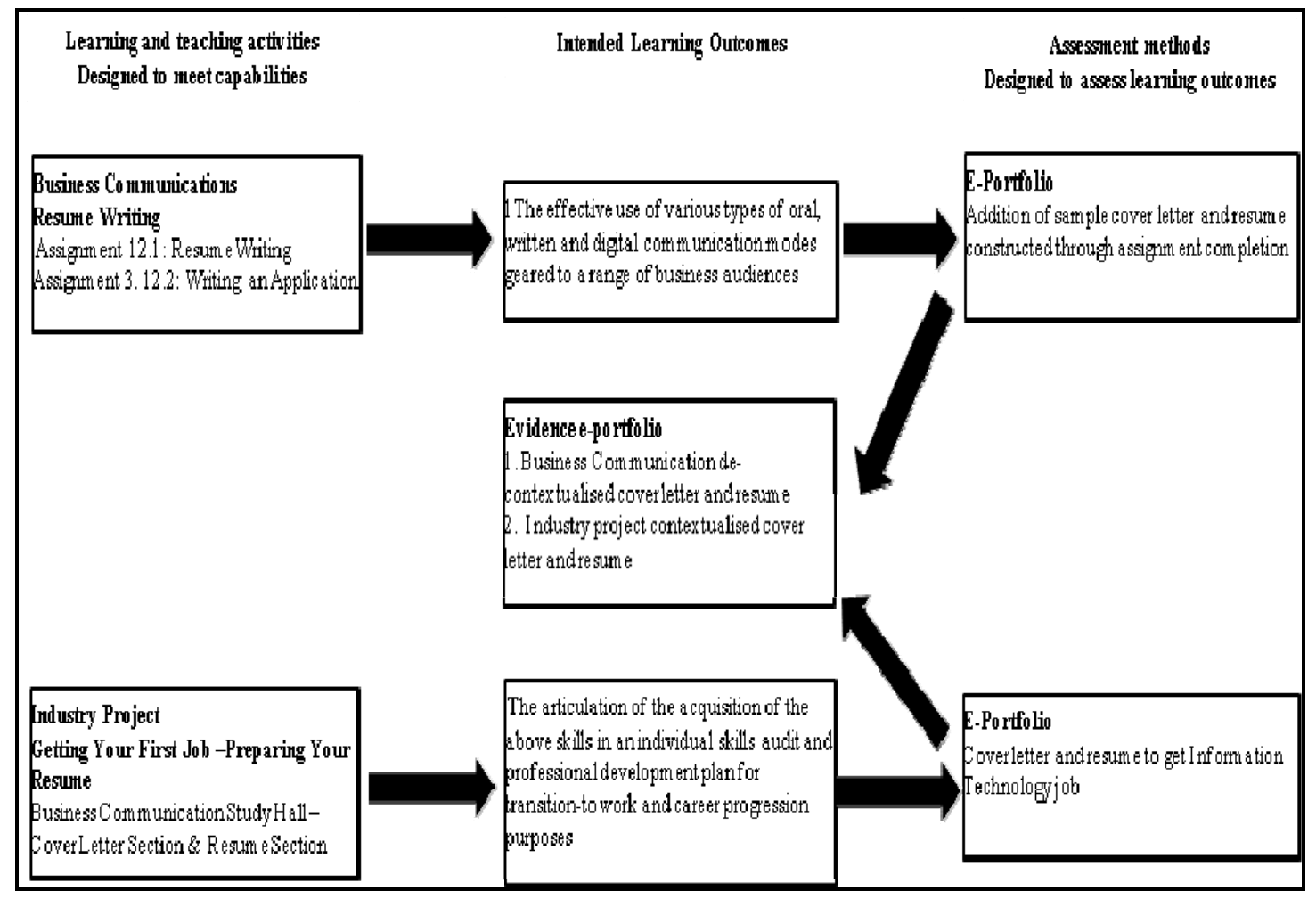

Figure 1. Resource Construction and Integration 
The solution was to use "CourseConnect" to provide the on-line components, complete with embedded lectures, assessment, quizzes and testing. In "Business Communications", the first subject, students completed the online activities to construct an e-portfolio containing a job application cover letter and resume. The students completing the course in Vietnam were studying Management or IS. In the second subject "Industry Project” these students completed the same task for the case included in the Study Hall. Finally, in the Industry Project, the student constructed a cover letter and resume to apply for a professional graduate position. Students were also given the opportunity to reflect on their own advancement and skills development. The learning activities were case-based with a mix of individual work and team work. Activities included workshops, practical exercises, simulations and field work.

The first level of customisation occurred when the components of the text, activities and online quizzes were identified for inclusion. During the creation of the assessment tasks required for constructional alignment to close the loop between the objectives and evidenced outcomes the professional case context was the focus. Whilst the academic saves time by identifying readymade skill and knowledge content during the custom publishing process, this time saved is necessary for the quality finish for the subject curricula.

The customised product created to support these two subjects combined the components of two original texts, supplemented by material sourced from a third text. Customisation over two subjects provided the opportunity for students to reflect on previous learning and refer back to work completed both in the Working Communications text and in their individual e-portfolios. The activities and assessment tasks were integrated to provide a more thorough coverage of important concepts and increased depth of learning without repeating concepts, theories and skills unnecessarily.

As technology allows more incremental customization it is predicted that the exponential growth of demand will continue, as will the re-focus of academic time. Technology allows academics to draw material from publisher's comprehensive database of copyright resources. In addition, the academic can choose to provide resources to students in a traditional text based form or as an e-book. The e-book allows for just-in-time and customized delivery to flexible, full color screens (via notebooks, netbooks, iPhones, iPads, laptops and desktop computers), and has the potential to provide audio and video components, the ability for handwriting, as well as margins for notetaking and text highlighting [Dennis et al, 2008].

Previous research has explored initial user perceptions and the use of Amazon's Kindle e-book reader [Egan, 2009]. The cost of an e-book is approximately 55\% of the price of a traditional text. Publishers provide a selection of titles via a joint web-based delivery ('Vital Source') and the sales of e-books are rising rapidly:

"The acquisition and exchange of data and information is designed to be as simple and efficient as possible, prompting the user for decisions only when necessary, and exchanging only information that is determined to be relevant to the user" [Huang et al, 2005].

Academic use of the highlighting and annotation features of the e-book application may improve uptake and use of available resources outside the classroom [Richardson et al, 2007]. Even more recently we have seen an increase in interest in the customization of media to accompany the custom textbook or to stand independently of a textbook. We've also seen growth in requests for ebook versions of custom content. Custom publishing allows the publisher to provide tailored solutions that really speak to the teaching and learning needs of the individual academic and student. 
Of note, a recent study of factors that may influence the adoption of digital resources such as ebook usage, found that students did not prefer e-books to text books regardless of previous use. Further, it was observed that e-book users were not likely to use e-book interactive features and pictures, where the case was different for text book based content (Woody, Daniel \& Baker, 2010). That study revealed that e-Book users still preferred text books for learning. The researchers do comment, however, that the learning outcomes were found to be much the same for e-book and text books users. It should be noted that the sample comprised 91 students at a medium-sized regional university. It presumably did not require the delivery of the same subject in different countries, with multiple deliveries in differing contexts, in a range of learning and teaching spaces, interacting with varied resource delivery modes, across geographical boundaries and within differing cultural environments. Clearly, further research needs to be undertaken in this domain.

\section{Results: Qualitative Survey - Some Academic Perspectives}

In the space available it is clearly not possible to report comprehensively the results of the survey conducted. A selection of highlights only are reported herein.

Pearson Education Australia launched its dedicated Custom Publishing program in 2004 and it has seen an average annual growth rate of $40 \%$ - the fastest growing part of the business. Custom texts can be made up of derivative or original material or a combination thereof. In the first year or so, source content was drawn primarily from textbook content at the chapter level and the selected content was re-ordered, reprinted and bound as a hard copy custom textbook. There was minimal editorial work undertaken. As reported above, for the "Working Communications" case, the sophistication of custom publishing has increased dramatically.

Indicative responses of academics to each of three key questions are reported in Table 1:

- Why did you choose a custom solution? Academics cited the ability to tailor the text to the course, rather than the course to the text, as key to the decision to undertake custom publishing. It is interesting, however, that an additional major advantage of a customized solution, cited by four of nine Australian academics interviewed was a reduction in costs for the students. In a climate where the rising costs of academic publications have become prohibitive for students, any process likely to reduce costs was seen as advantageous to the learning environment. Resources that did not align with the subject topic schedule were not included in the publication. Further, publishing in black and white rather than color also resulted in decreased costs to students. These strategies were seen to influence the students' choice to purchase.

- What difference did the customized content make to students? In response, academics highlighted that students did not have to search for, or acquire multiple texts. As the academic market has become used to the concept of customization academics have sought more extensive customization, which has usually required re-editing and redesigning of the source content to ensure it fits together in a more cohesive manner. Indeed, academics are now able to incorporate their own contextualized resources and have them professionally packaged within the purchased text, to meet local student needs. This is an absolute necessity to enable a re-configuring of the narrative and to ensure the alignment of specific assessments to the learning objectives and activities. Every customized solution still provides an aesthetically designed cover and layout, readable type, well-written copy and appropriate language for the level of learning [Speckler, 2008]. 
- Was it successful? Academic responses were resoundingly “yes”, for all the reasons cited above.

Table 1. Academic Perspectives Custom Publishing

\begin{tabular}{|c|c|c|}
\hline Questions & Respondent & Quote \\
\hline \multirow[t]{2}{*}{$\begin{array}{l}\text { Why did you choose a } \\
\text { Custom solution for } \\
\text { your course? }\end{array}$} & $\begin{array}{l}\text { Academic Re- } \\
\text { spondent } 2\end{array}$ & $\begin{array}{l}\text { The option to Custom a book was preferred because it en- } \\
\text { sured a text that was tailored to meet the requirements of my } \\
\text { course and hence best suit my students' educational needs. }\end{array}$ \\
\hline & $\begin{array}{l}\text { Academic Re- } \\
\text { spondent } 4\end{array}$ & $\begin{array}{l}\text { The flexibility is important because it enables me to tailor the } \\
\text { text to my course rather than tailoring my course to reflect } \\
\text { and incorporate the text. }\end{array}$ \\
\hline \multirow[t]{2}{*}{$\begin{array}{l}\text { What difference did } \\
\text { the Customised con- } \\
\text { tent make to your } \\
\text { students? }\end{array}$} & $\begin{array}{l}\text { Academic Re- } \\
\text { spondent } 8\end{array}$ & $\begin{array}{l}\text { The students need not search, locate or purchase multiple } \\
\text { textbooks and references, and had them all in a compiled } \\
\text { form for learning. Furthermore, students' request for addi- } \\
\text { tional information can be included in the preparation of the } \\
\text { next customized text. }\end{array}$ \\
\hline & $\begin{array}{l}\text { Academic Re- } \\
\text { spondent } 6\end{array}$ & $\begin{array}{l}\text { Not one student has said that buying the book was a waste of } \\
\text { time - and there are over } 300 \text { of them. They have found the } \\
\text { content specific and relevant to their ongoing teaching re- } \\
\text { quirements. }\end{array}$ \\
\hline \multirow[t]{2}{*}{$\begin{array}{l}\text { Was it successful? } \\
\text { Why/Why not? }\end{array}$} & $\begin{array}{l}\text { Academic Re- } \\
\text { spondent } 3\end{array}$ & $\begin{array}{l}\text { Yes, it was successful for the reasons stated above. The } \\
\text { drawbacks are black and white printing to keep costs down } \\
\text { and certain sections such as glossary and answers to all chap- } \\
\text { ter questions omitted, also to keep costs down. However, } \\
\text { with several copies of each of the full texts available in the } \\
\text { XXX library on short access loan, all these problems can be } \\
\text { overcome by the students accessing the books as they need }\end{array}$ \\
\hline & $\begin{array}{l}\text { Academic Re- } \\
\text { spondent } 6\end{array}$ & $\begin{array}{l}\text { The book is successful because it is customized, which means } \\
\text { every chapter is included as part of the unit. For example, } \\
\text { there are weekly readings, reflection activities and discus- } \\
\text { sions around the set chapters, with the focus coming directly } \\
\text { from the book, rather than me having to devise appropriate } \\
\text { responses to the text. The major assessment, an electronic } \\
\text { portfolio, also includes mandatory inclusions from the text- } \\
\text { book. Every part of the book is utilized. }\end{array}$ \\
\hline
\end{tabular}

\section{Conclusion}

This paper has captured the perspectives of a key participant group in creating the future of custom texts: the academics who design teaching and learning deliverables for the custom texts, with a focus on constructive alignment in subject delivery.

The paper has made the point that in order to create and facilitate measurable work based learning tasks that ensure 'work ready' graduates, all of the workplace skills cited in this paper must be addressed. Designing and implementing activities and assessments that embed generic professional capabilities, academic theories and concepts, and the needs of industry, is a complex task. Creative ICT solutions in industry necessitate students being equipped with IT specialist knowledge, an ability to communicate effectively and general business knowledge together with the capacity to problem solve. Students not only embrace technology and customized solutions they expect them. Customization of academic resources using the vast databases of copyright material and technologies to support download and communication, has changed the academic 
resource development landscape. The fact that the resources purchased from publishers can be used flexibly and align with the academic individual needs, rather than academics designing content around texts, enables constructive alignment in subject delivery.

\section{References}

Australian Computer Society (ACS) (2009). Professional Standards Board - The ICT Profession Body of Knowledge URL: http://www.acs.org.au/attachments/ACSCBOKWorkingPaperV5.0Oct2008.pdf

Beckett, D. \& Hager, P. (2002). Life, Work and Learning: Practice in post modernity, London \& New York, Routledge.

Benbasat, I. Goldstein, D. \& Mead, M. (1987). "The Case Research Strategy in Studies of Information Systems”, MIS Quarterly, (11:3), 369-386.

Biggs, J. B. (2003). “Teaching for quality learning at university: What the student does”, in Society for Research into Higher Education/Open University Press, Philadelphia: Buckingham, USA.

Bloom, B. S. (1956). Taxonomy of Educational Objectives, Handbook I: The Cognitive Domain. David McKay Co Inc, .New York, USA, 1956.

Dennis, T. Clark, D. T. Goodwin, S. P. Samuelson, T. \& Coker, C. (2008). A qualitative assessment of the Kindle e-book reader: results from initial focus groups, Performance Measurement and Metric, (9:2), 2008, 118-129.

DEST (2002). Employability Skills for the Future. Commonwealth of Australia.

Egan, C. (2009). “Students to dump textbooks for e-books,” The Sunday Age, 16 August, 5, 2009.

Henderson, F. \& McWilliams, A. (2008). "Enhancing student engagement with industry: a curriculum approach to scaffolding employability skills", in Work Integrated Learning (WIL): Transforming futures, WACE Asia Pacific Conference, The Australian Collaborative Education Network (ACEN), Sydney, Australia, 47-60.

Huang, A. Pulli, K. \& Rudolph, L. Kimono (2005). Kiosk-Mobile Phone Knowledge Sharing System”, in Massachusetts Institute of Technology, Nokia Research Centre, HIT Lab NZ, University of Canterbury, Christchurch, New Zealand.

Jaques, E.(1976). "Learning for uncertainty, emotions and behaviour”, in Monograph Series 9 of the Chicago Institute for Psychoanalysis, Madison Publishers, Chicago, USA, 149-169.

Marginson, S.(1994). "Transfer of skills and knowledge: the key to improving the relationship between education and work", in Thinking work, Volume 1: Theoretical perspectives on workers' literacies, P. (Ed.), Adult Literacy and Basic Skills Action Coalition, Sydney, Australia, 1994, Chapter 12, 235-256.

McBurney, D,H. (2001). Research Methods, Thompson Learning, Wadsworth, Australia, 2001.

Ramsden, P. (1992). Learning to Teach in Higher Education. Routledge, London, England, 1992.

Richardson, J. \& Lenarcic J. (2007). "E-inclusion through text messaging: The emergence of an administrative ecology within a university student population via the use of a mobile academic information delivery system”, Proceedings of the 20th Bled eConference, June 4-6, Bled, Slovenia.

Seoul Accord (2007). Mutual recognition of Educational programs in the Computing and IT-related Disciplines - Graduate Attributes, November 2007, URL:

http://www.abeek.or.kr/accord/contents.jsp?menu_l=144\&menu_m=199

Speckler, M. (2008). "Vision in Action - How Pearson Custom Publishing Works in Higher Education”, Pearson, Boston, MA.

Woody, William Douglas, Daniel, David B. \& Baker, Crystal A. (2010). "E-books or textbooks: Students prefer textbooks”, Computers and Education, 55, 945-948. 
Yin, R. K. (2002). Case Study Research, Design and Methods, 3rd ed. Sage Publications, Thousand Oaks, California, USA.

\section{Biographies}

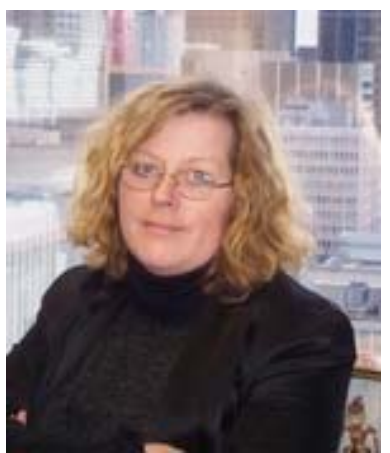

Associate Professor Joan Richardson is a member of the School of Business IT and Logistics, RMIT University, Australia. She has led strategically aligned university projects that require technology or systems changes/improvements to staff work-practice and the student learning experience. These have ranged from business systems that enable efficient benchmarking of programs against accreditation requirements, to the development of suites of curriculum resources delivered using emerging technologies. Her passion for new technology innovation, expertise as a Business Analyst and extensive operational experience, enables significant contributions to the Information Systems (IS) discipline in industry.

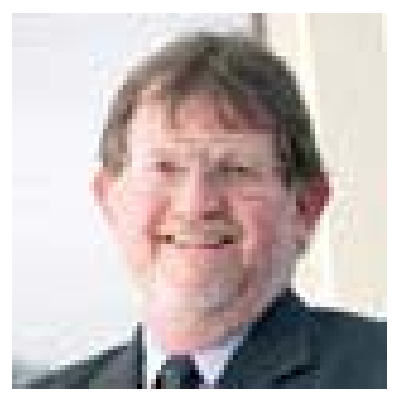

Dr Ross Smith has been a member of faculty at the Australian National University, Swinburne University of Technology, Deakin University and, since January 2007, at RMIT University, Australia. He has taught widely across the curriculum in areas such as business computing, systems analysis and design, supply chain management, software engineering, systems implementation, and software project management. Ross has researched and published on the practice of Work Integrated Learning (WIL) in the education of the IS professional.

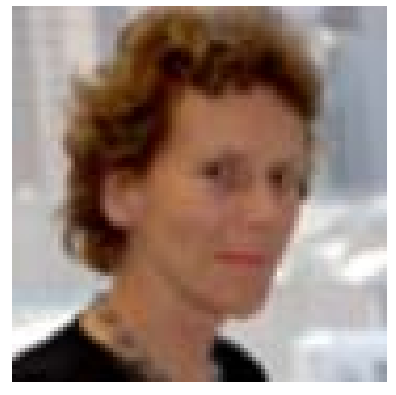

Audra Lukaitis is a member of faculty in the School of Business IT and Logistics, RMIT University, Australia and is a founding member of the school. She has been teaching, consulting and researching in ICT for many years.

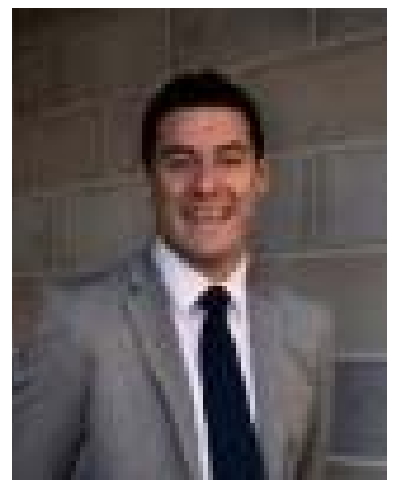

Ryan O'Hare is the Higher Education Learning Solutions Manager for Pearson Learning Solutions. His role involves working with Universities and Institutions on needs and solutions, away from the traditional textbook model for which Pearson is renowned. The Learning Solutions Division has been created to work in partnership with many Australian universities on such projects. 